\title{
Atherosclerosis and atherosensitivity in two southwest Algerian desert rodents, Psammomys obesus and Gerbillus gerbillus, and in Rattus norvegicus
}

\author{
This article was published in the following Dove Press journal: \\ Diabetes, Metabolic Syndrome and Obesity:Targets and Therapy \\ 17 September 2012 \\ Number of times this article has been viewed
}

\author{
Salima El-Aoufi ${ }^{1}$ \\ Mohamed-Amine \\ Lazourgui' \\ Lakhdar Griene ${ }^{2}$ \\ Boubekeur Maouche ${ }^{3}$ \\ 'Laboratoire de Biologie et de \\ Physiologie des Organismes/MMDED, \\ Faculté des Sciences Biologiques, \\ USTHB, El-Alia, Dar El Beida, Algeria; \\ 'Laboratoire d'Hormonologie, \\ Centre Pierre et Marie Curie, C.H.U \\ Mustapha, Algeria; ${ }^{3}$ Laboratoire de \\ Physicochimie Théorique et Chimie \\ Informatique, Faculté de Chimie, \\ USTHB, El-Alia, Dar El Beida, Algeria
}

Correspondence: Salima El-Aoufi Laboratoire de Biologie et de Physiologie des Organismes/MMDED, Faculté des Sciences Biologiques, USTHB, El-Alia BP 32, Dar El Beida, I6 I I I, Algeria

$\mathrm{Tel}+213661173618$

Fax +21321247311

Emailsmelaoufi@yahoo.fr

\begin{abstract}
Cardiovascular disease, including atherosclerosis, is the leading cause of death in patients with diabetes worldwide; thus, it is a major medical concern. The endothelium contributes to the control of many vascular functions, and clinical observations show that it is a primary target for diabetic syndrome. To get better insight into the mechanisms underlying atherosclerosis, we studied the interspecific differences in the arterial metabolisms of two, Psammomys obesus and Gerbillus gerbillus, as well as Rattus norvegicus (Wistar rat), well known for its atheroresistance. Twenty-two enzymatic activities and six macromolecular substances were histochemically compared in the two desert species and in Wistar aortas (abdominal and thoracic) and arteries (femoral and caudal) embedded in a common block. In the healthy adult rodents, enzyme activities were very intense. They demonstrated that aortic myocytes are capable of various synthesis and catabolism processes. However, considering the frequency of atherosclerosis and its phenotypes, significant differences appeared between the species studied. Our comparative study shows that aortic atherosensitive animals have several common metabolic characteristics, which are found in Psammomys rich in metachromatic glycosaminoglycans (involved in the inhibition of lipolysis and in calcification of the organic matrix), reduced activity in enzymes related to the Krebs cycle (weakening energetic power), and low lipolytic enzyme, adenosine triphosphatase, and adenosine diphosphatase activities. However, the most fundamental pathophysiological difference is the low lipolytic power of the aorta of Psammomys when compared to Wistar rats. This characteristic determines its atherosensitivity and makes this animal model more applicable to the experimental development of atherosclerosis.
\end{abstract}

Keywords: diet-induced diabetes, CVD, atherosensitivity, artery enzymatic activities, histochemistry, Psammomys obesus

\section{Introduction}

Cardiovascular disease is the leading cause of death in patients with type 1 or type 2 diabetes mellitus (T2D) worldwide; thus, it is a major medical concern. The endothelium contributes to the control of many vascular functions, and clinical observations show that it is a primary target for diabetic syndrome (DS). In humans, abnormalities in endothelium-dependent vasodilatation have been demonstrated in diabetics in all vascular areas, and the presence of endothelial dysfunction is an independent predictive factor of the occurrence of cardiovascular events. Integrated experimental work on animal models demonstrates that endothelial dysfunctions are responsible for cardiac 
and vascular remodeling, eventually leading to the loss of coherence in the hemostasis system, which is responsible for thrombosis. ${ }^{1}$ However, the underlying causes of diabetic macrovascular pathogenesis have not yet been well established. ${ }^{2}$ Animal models, in which some features of diabetes and atherosclerosis diseases have been induced, are therefore useful and advantageous in biomedical studies because they promise new insights into human diabetes. Unfortunately, it is well known that no animal model completely mimics the human pathology since most rodents used develop only small vascular lesions, sometimes limited to the stage of simple fatty streaks. ${ }^{3}$ It is only through streptozotocine injection that diabetes is induced, and a few weeks later, more complex and extensive lesions resembling those described in humans develop. However, the specific abnormalities of T2D are directly related to chronic hyperglycemia, ${ }^{4}$ and more particularly, to the glycation of amine endings of the proteins of the basement membrane; the sudden change from a healthy state to an insulin-dependent and sclerotic state does not allow us to identify the different entities, often unstable, generated during the intermediate stages in the pathway of the Maillard reaction. ${ }^{5}$ Yet, although no model completely mimics the human pathology, some species of Gerbillinaes living in extreme conditions, like Gerbillus gerbillus (Gerbillus) and Psammomys obesus (Psammomys), have often served as experimental models in the domain of comparative physiology for diseases related to DS. The phenotypes of histological disorders observed in the target organ tissues of these animals affected by one of the consequences of DS indeed closely resemble those described in humans. ${ }^{6-9}$ In fact, recent works show that Psammomys is the most appropriate model animal for experimentation in diet-induced obesity and diabetes; it is also very often used as a model to study other human diseases, such as neuronal degeneration and cerebral ischemia and its consequences, ${ }^{10-12}$ as well as in hearing studies. ${ }^{10-12}$

All these gerbil species live in comparable semi-desert biotopes of North Africa, the Eastern Mediterranean, and southern Asia. They are generally the only stocking of rodents in the dune sands. Among these gerbils, Gerbillus gerbillus (Olivier 1801) is the predominant species. It occupies all the covered areas of a steppe scattered with shrubs (Atriplex halimus) and with perennial grass, but may be also found in rocky terrain or saline marsh areas. Psammomys obesus (Cretzs 1828) is a rarer species, closely related to the semi-desert steppe. They live in burrows that are often located under the bushes in which the rats forage, such as the salty bushes of the Chenopodiaceae family, rich in sodium chloride and low in calories like Traganum nudatum, Suaeda mollis, and Salsola foetida. These plants are also well known for their antioxidant properties due to the phenolic compounds contained in their leaves, as has been recently confirmed. ${ }^{13}$ These animals, living in drastic climatic and nutritional conditions, develop comparable adaptive, behavioral, and physiological strategies that allow them to live and develop normally in such biotopes. However, these gerbils, even though they have adapted to the same desert environment, do not have the same metabolic characteristics. The observation of the frequency and the morphological aspects of atherosclerosis in laboratory animals show that there are considerable differences from one species to another. This different behavior cannot be fully explained by the involvement of environmental, nutritional, or serum factors. Many histochemical and biochemical works suggest that the characteristics of the arterial metabolism of different species are determining factors in their atherosensitivity. ${ }^{14}$ These considerations prompted us to examine the arterial metabolisms of the desert rodents, Psammomys and Gerbillus, and compare them with that of Wistar rats (Rattus norvegicus), which are considered an atheroresistant animal model.

\section{Material and methods \\ Animals}

In this study, we used adult (from 3 to 6 months) Psammomys (50) and Gerbillus (25) gerbils of both sexes, trapped in the semi-desert region of Beni-Abbes-Abadla $(900 \mathrm{~km}$ south-west of Algiers) and adapted to laboratory conditions $\left(25^{\circ} \mathrm{C}, 70 \%\right.$ hygrometry, and a 12 -hour light-dark cycle), and 10 Wistar rats. Upon their arrival in the laboratory, the two gerbil species were numbered, weighed, and transferred to separate suitable cages. After a two-week acclimation period, during which they were fed halophytes, Traganum nudatum, Suaeda mollis, and Salsola foetida (50 g/d/animal, equivalent to 30-32 kcal), they were randomly distributed into two groups: a control group of 10 Psammomys, maintained with a natural diet (ND); and the remaining Psammomys (40), Wistar (10), and gerbils (25), which were fed a standard laboratory chow (15-20 g/d/animal, equivalent to $52-70 \mathrm{kcal})$ and salty water $(0.9 \% \mathrm{NaCl})$ ad libitum.

This diet is highly caloric (HCD) for the Psammomys, but not for the Gerbillus or the Wistar rats. Table 1 shows the composition of each diet. Halophyte plants are characterized by a very high content of water and salt (particularly $\mathrm{NaCl}$ ) and low calorific value (about $450 \mathrm{kcal} / \mathrm{kg}$ of fresh plant). Due to the peculiarity of its diet, and particularly effective 
Table I Natural diet (ND) and hypercaloric diet (HCD)

\begin{tabular}{llll}
\hline ND & Composition (\%) & HCD & Composition (\%) \\
\hline Water & 80.79 & Water & 9.0 \\
Minerals & 6.86 & Minerals & 7.1 \\
Fats & 0.40 & Fats & 7.5 \\
Proteins & 3.53 & Proteins & 25 \\
Carbohydrates & $8.42 *$ & Total sugars & $47.43 * *$ \\
Total sugars & 0.18 & Cellulose & 4.0 \\
Hemicellulose & 2.62 & & \\
Cellulose & 2.23 & & \\
Lignine & 1.12 & \\
Undetermined & 2.27 & \\
\hline Notes: $*$ The carbohydrates (total sugars, lignine, cellulose, hemicelluloses, and \\
undetermined quantities) constitute $8.42 \%$ of the total composition; **rate of useful \\
carbohydrate used $=100$ - rate of: crude protein + fat + ash + cellulose + humidity.
\end{tabular}

kidneys, which allow it to significantly reduce water $\operatorname{loss}^{15}$ Psammomys never drink water in their biotope.

All our animals were treated according to Directive $86 / 609 / E E C$, which regulates the use of animals for experimental and other scientific purposes, and which was adopted in the EU in $1986 .{ }^{16}$

\section{The histoenzymologic methods Methodology}

After being anesthetized with nembutal, the animals were bled, and their arteries quickly dissected. Fragments of the upper thoracic aorta and the abdominal aorta and the femoral and caudal arteries were removed, and juxtaposed in the same block so that several samples from the three species could be compared on the same cup. The common blocks were immersed in liquid nitrogen for 10 seconds, then cryostat sections of 8 microns were prepared using a PMV CryoMicrotome 2550 (LKB Co, Stockholm, Sweden).

For the histochemical studies, fragments adjacent to the fragments collected for the study were set in Dubosq-Brasil in paraffin and cut at 5 microns. The following macromolecular substances and enzymatic activities were studied after the application of the appropriate histochemical methods. To avoid enzyme leakage and prevent decline in activity and false location, various methods were used:

- After a period in pure acetone and rinsing with an appropriate buffer, the sections were incubated in conventional media for the detection of dehydrogenase (DH) and esterase.

- For redox reactions, nicotinamide adenine dinucleotide (NAD) and nicotinamide adenine dinucleotide phosphate (NADP) (Boehringer, Mannheim) were the intermediate electron acceptors, while Nitro Blue tetrazolium III (nitro-BT III) and tetra-nitro BT (Sigma, St Louis, MO) were the final electron acceptors. To reduce the diffusion of soluble enzymes in the medium, we added an aliquot of $6 \%$ agar. The incubation time at $17^{\circ} \mathrm{C}$ was prolonged (20 min). For each histoenzymatic reaction, a "witness" cut was incubated in the absence of a specific substrate. The intensity of these reactions was expressed by indices of positivity: $0,1,2,3,4$, and 5, indicating, respectively, barely positive, positive, weak, moderate, intense, and very intense reactions.

\section{Macromolecular substances}

Glycoproteins and other carboxyhydrates: periodic acid Schiff's reaction (PAS) with and without the digestion test with alpha- and beta-amylase,${ }^{17}$ glycogen: was demonstrated by the dimédon PAS technique; ${ }^{18}$ glycosaminoglycans (GAG): toluidine blue (Merck) $0.2 \% \mathrm{pH}=2,4$, and 6 ; ribonucleoproteins Unna-Pappenheim method with Brachet's test: ${ }^{17}$ fatty acids and neutral lipids: Nile blue sulfate "Gurr" $1 \%$ Sudan black staining.

\section{Enzymatic activities \\ Oxydoreductases}

1,1,1,8-Glycerol-3-phosphate DH, 1,1,1,30,3-hydroxybutyrate dehydrogenase, 1,6,4,3-nicotinamide adenine dinucleotide dehydrogenase (NADH DH), 1,6,99,1-nicotinamide adenine phosphate dinucleotide dehydrogenase (NADPH DH), and 1,4,1,4-glutamate $\mathrm{DH} ;{ }^{19}$ 1,1,1,27-lactate $\mathrm{DH} ;{ }^{20}$ Isocitrate $\mathrm{DH} ;{ }^{21}$ 1,1,1,49-glucose-6-phosphate dehydrogenase (G6PD); ${ }^{22}$ 1,3,99succinate $\mathrm{DH} ;{ }^{23}$ 1,4,3,4-monoamine oxidase (MAO) ${ }^{24}$

\section{Transferases}

2,4,1,1-Glycogen phosphorylase, ${ }^{25}$ 2,4,1,11-Uridine diphosphate glucose (UDPG)-glycogen synthase. ${ }^{26}$

\section{Hydrolases}

3,1,1,1- $\alpha$-Naphthyl acetate esterase, ${ }^{23} 3,1,1,8$-cholinesterase, ${ }^{27}$ 3,1,3,1-alkaline phosphatase and 3,1,3,2-acid phosphatase; ${ }^{28}$ 3,1,3,5,5'-nucleotidase, ${ }^{29}$ 3,2,1,31-beta-glucuronidase; ${ }^{30} \mathrm{Mg}^{2+}$ ATPase and $\mathrm{Ca}^{2+}$-ATPase; ${ }^{31}$ 3,6,1,7-arylsulfatase, ${ }^{32}$ adenosine polyphosphatase: ${ }^{33} 3,4,1,1$-leucine aminopeptidase. ${ }^{34}$

\section{Results \\ Histochemistry and histoenzymology of the arterial tissue of the three species Methodology}

To search for interspecific differences in the arterial metabolism in Psammomys, Gerbillus, and Wistar rats, four arterial segments of each of these species were juxtaposed in the same 
block, sectioned, histochemically processed together, and then observed and compared on the same section. Thus, any differences that would appear would be characterized by a sure value. The results are shown in Table 2 and in Boards 1 to 3 of Figure 1. These results provide information about the metabolic behavior of arterial tissue of adult Psammomys and they highlight the differences between this animal and the two other rodent species.

\section{Features of the metabolism of Psammomys obesus}

As in the other species, the smooth muscle cells (SMCs) in the desert rodent media were, histoenzymatically, the most active parietal element. In the healthy adult animals, enzyme activities were very intense. They demonstrated that aortic myocytes can achieve various synthesis processes (glycosaminoglycans, glycoproteins, lipids), and various types of catabolism (glycolysis, esterolysis, lipolysis). The myocyte enzymes contributed to the maintenance of balance between humoral inputs and the metabolic systems of the aortic wall and a better adaptation of cells to biochemical alterations occurring with age.

In adult animals, the myocytes' oxidative metabolism was dominated by glycolysis, lactate and $\alpha$-glycerophosphate dehydrogenase being more intense than the oxidoreductases linked to the aerobic degradation of glucose in the pentose pathway glucose-6-phosphate-dehydrogenase (G6-PDH); and in the Krebs cycle, succinate dehydrogenase (SDH) and isocitrate dehydrogenase (ICDH). Glycogen metabolism

Table 2 Histochemical and histoenzymologic parameters of abdominal and thoracic aortas, and femoral and caudal arteries of Psammomys obesus, Gerbillus gerbillus, and Wistar rats

\begin{tabular}{|c|c|c|c|c|c|c|c|c|c|}
\hline \multirow[t]{3}{*}{ Parameters } & \multicolumn{6}{|c|}{ Aortas } & \multicolumn{3}{|c|}{ Arteries } \\
\hline & \multicolumn{3}{|c|}{ Thoracic } & \multicolumn{3}{|c|}{ Abdominal } & \multirow{2}{*}{$\frac{\text { Caudal }}{P(40)}$} & \multicolumn{2}{|c|}{ Femoral } \\
\hline & $P(40)$ & $\mathbf{G}(25)$ & $\mathbf{R}(10)$ & $P(40)$ & $\mathbf{G}(25)$ & $\mathbf{R}(10)$ & & $\mathbf{G}(25)$ & $\mathbf{R}(10)$ \\
\hline \multicolumn{10}{|l|}{ Oxydoreductases } \\
\hline Glucose G6-PDH & 2.5 & 1.5 & 2 & 2.5 & 1.5 & 2 & 2.5 & 2.5 & 2.5 \\
\hline$\alpha$-Glycerol 3-PDH & 3.5 & 3.5 & 0.5 & 3 & 2.5 & 1 & 3 & 2 & 1.5 \\
\hline Lactate $\mathrm{DH}$ & 3 & 3 & 2.5 & 3 & 3 & 2.5 & 3.5 & 3 & 3 \\
\hline$\beta$-H Butyrate DH & 1 & 1 & 1 & I & 1 & 1 & 1.5 & 1.5 & 1.5 \\
\hline Isocitrate DH & 2.5 & 2 & 1.5 & 2.5 & 2.5 & 1.5 & 3 & 3 & 3 \\
\hline Succinate DH & 3 & 2.5 & 2 & 3 & 3 & 1.5 & 3.5 & 3.5 & 3 \\
\hline Glutamate DH & 2.5 & 2.5 & 2 & 3 & 3 & 2.5 & 3.5 & 3.5 & 3 \\
\hline $\mathrm{NADPH}_{2} \mathrm{DH}$ & 3 & 2.5 & 2 & 3 & 2.5 & 2 & 3 & 3 & 3 \\
\hline NADH DH & 3 & 2.5 & 2 & 3 & 3 & 2.5 & 3 & 3 & 3 \\
\hline Monoamine oxidase & 2 & 2 & I & 2 & 2 & I & 2 & 2 & 2 \\
\hline \multicolumn{10}{|l|}{ Transferase } \\
\hline UDPG-synthetase & 0.5 & 0.5 & 0.5 & 0.5 & 0.5 & 0.5 & I & I & I \\
\hline Phosphorylase & 1.5 & 1 & I & 1.5 & I & I & 1.5 & 1 & 1 \\
\hline \multicolumn{10}{|l|}{ Hydrolases } \\
\hline Alkaline phosphatase V.V & 0 & 0 & 3 & 0 & 0 & 3 & 0 & 0 & 3 \\
\hline $5^{\prime}$ nucleotidase & 0.5 & 0.5 & 1.5 & 0.5 & 0.5 & 1.5 & 0.5 & 0.5 & 1.5 \\
\hline ATPase $\mathrm{Ca}++$ & 3.5 & 3.5 & 3.5 & 3.5 & 3.5 & 3.5 & 3 & 3 & 3 \\
\hline Indoxylesterase & 0.5 & $\mathrm{I}$ & 1.5 & 0 & $\mathrm{I}$ & 1.5 & 0 & 0 & 0.5 \\
\hline Naphtylesterase & I & 1.5 & 2 & 0.5 & 1.5 & 2 & 0 & 0.5 & 0.5 \\
\hline Cholinesterase & 0.5 & 1.5 & 2 & I & 1.5 & 2 & 0 & 0 & 0 \\
\hline Acid phosphatase & 0.5 & 0.5 & 0.5 & 0.5 & 0.5 & 0.5 & 0.5 & 0.5 & 0.5 \\
\hline LA peptidase & 1.5 & 1.5 & 0.5 & 0.5 & 0.5 & 0.5 & 0.5 & 0.5 & 0.5 \\
\hline Arylsulfatase & 4 & 4 & 4 & 4 & 4 & 4 & 2 & 2 & 2 \\
\hline$\beta$-glucoronidase & 1 & 1 & 1 & 1 & 1 & 1 & 0 & 0 & 0 \\
\hline \multicolumn{10}{|l|}{ Macromolecules } \\
\hline PAS+ substances & 2 & 2 & 2 & 2 & 2 & 2 & 1.5 & 1.5 & 1.5 \\
\hline Glycogen & 0 & 0 & 0 & 0 & 0 & 0 & 0 & 0 & 0 \\
\hline Glycosaminoglycans & 2 & 2 & 2 & 2 & 2 & 2 & I & 1 & I \\
\hline Neutral lipids & 0 & 0 & 0 & 0 & 0 & 0 & 0 & 0 & 0 \\
\hline Fatty acids & 0 & 0 & 0 & 0 & 0 & 0 & 0 & 0 & 0 \\
\hline RNA & I & I & I & I & I & I & 1.5 & 1.5 & 1.5 \\
\hline
\end{tabular}

Notes: The number of animals studied is given in brackets. The numbers given in the table indicate the average of the "index of positivity" of the reaction, resulting in several observations.

Abbreviations: P, Psammomys obesus; G, Gerbillus gerbillus; R, Wistar rat; V.V, Vasa vasorum. 


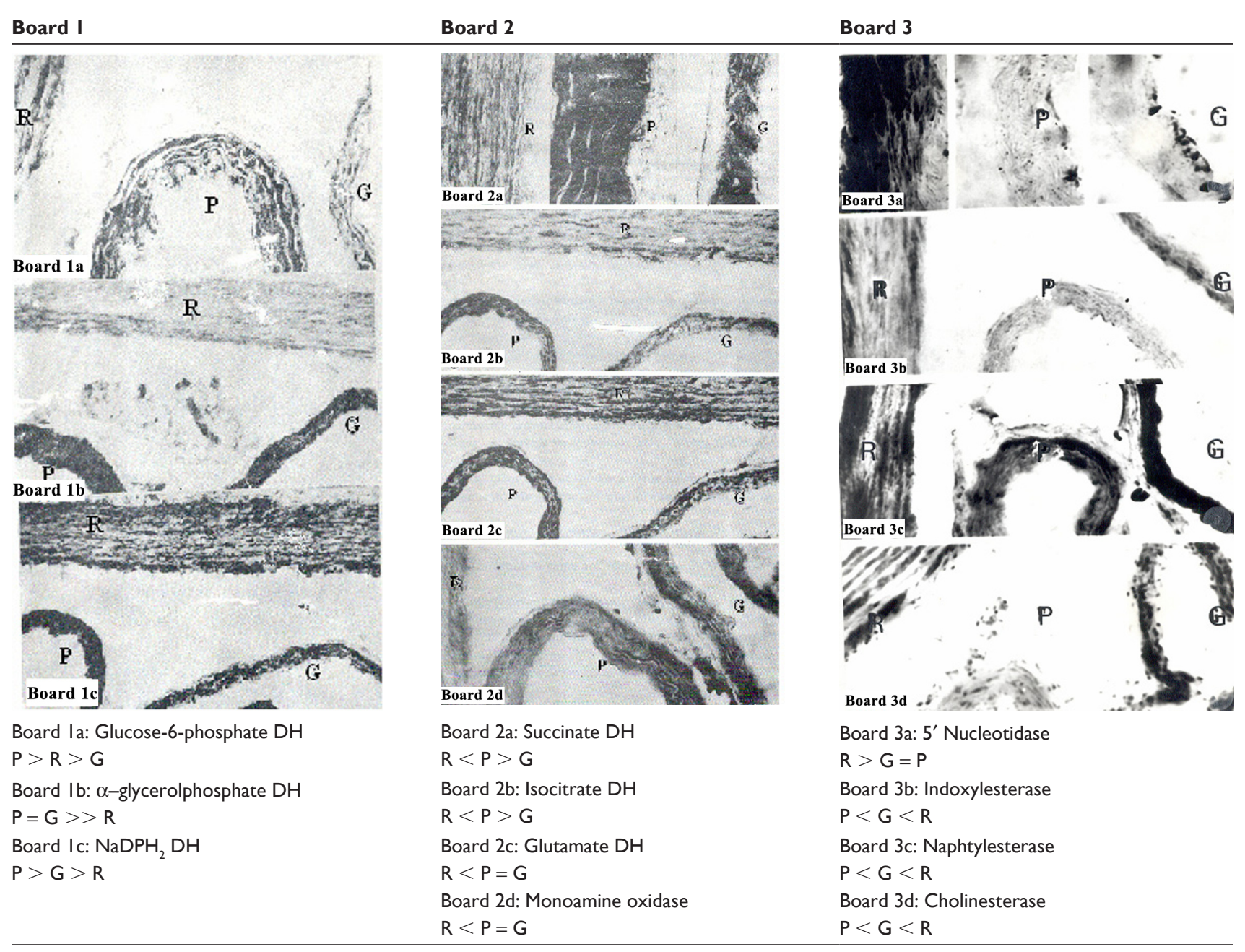

Figure I Interspecies differences of aortic enzymes of Psammomys, Gerbillus gerbillus, and Wistar rats. Abbreviations: P, Psammomys; G, Gerbillus; R, Wistar rats.

was reflected by uridine diphosphoglucose UDPG-glycogen synthase (anabolic enzyme) and glycogen phosphorylase (catabolic enzyme). These two activities were very weakly positive. This suggests that glucose that penetrated the media of Psammomys was metabolized and used for energy needs, rather than transformed and stored as glycogen. The latter was not shown histochemically. The phosphate adenosine esterolysis was useless concerning adenosine monophosphate AMP and very intense for adenosine-5'-triphosphate ATP, ATPase being very active in myocytes. The lipolytic enzymes (acid esterase, cholinesterase) were weakly positive. The hydrolysis of carboxylic esters must be very small when referring to the extremely low activities of acid esterases and cholinesterase. Lysosomal enzymes were unequally active: acid phosphatase (a classic marker of lysosomes) was barely detectable. Aminopeptidase and beta-glucuronidase were better represented. Arylsulfatase was extremely active and aminopeptidase was very intense in the fibroblasts of the adventitia for which it revealed itself as a true enzyme marker. Monoamine oxidase (MAO) was clearly positive, suggesting that the cells in the Psammomys media were capable of oxidative deamination of vasoactive monoamines (catecholamines).

Contrary to what has been observed in rabbit aorta (which are atherosensitive), the enzymatic activities in the aerobic oxidative degradation path of glucose, the Krebs cycle (SDH, IDH, and GDH), and the pentose pathway (G6PDH) were higher in Psammomys than in Wistar rats. ${ }^{35}$

Concerning the macromolecules, the media free of lipids appeared moderately rich in GAGs and in PAS+ substances (glycoproteins). The myocyte cytoplasm was relatively poor in RNA. This suggests that the synthesis activities in the adult animal would be slowed down, and that the enzymatic exaltation observed in various pathways of intermediary metabolism is mainly related to the permanent tonic character of the arterial myocytes and to the naturally hypertensive character of Psammomys. 


\section{Board 4}

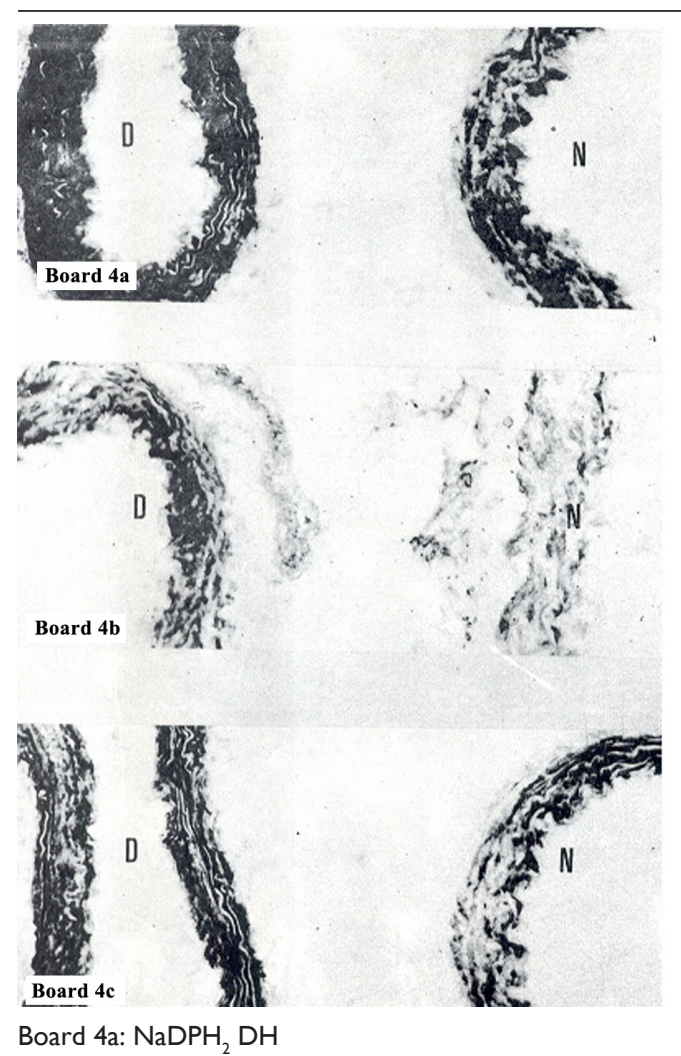

Board 4b: Glutamate DH

Board 4c: Malate DH

Higher activity in animals subjected to diabetogenic diet (D)
Board 5

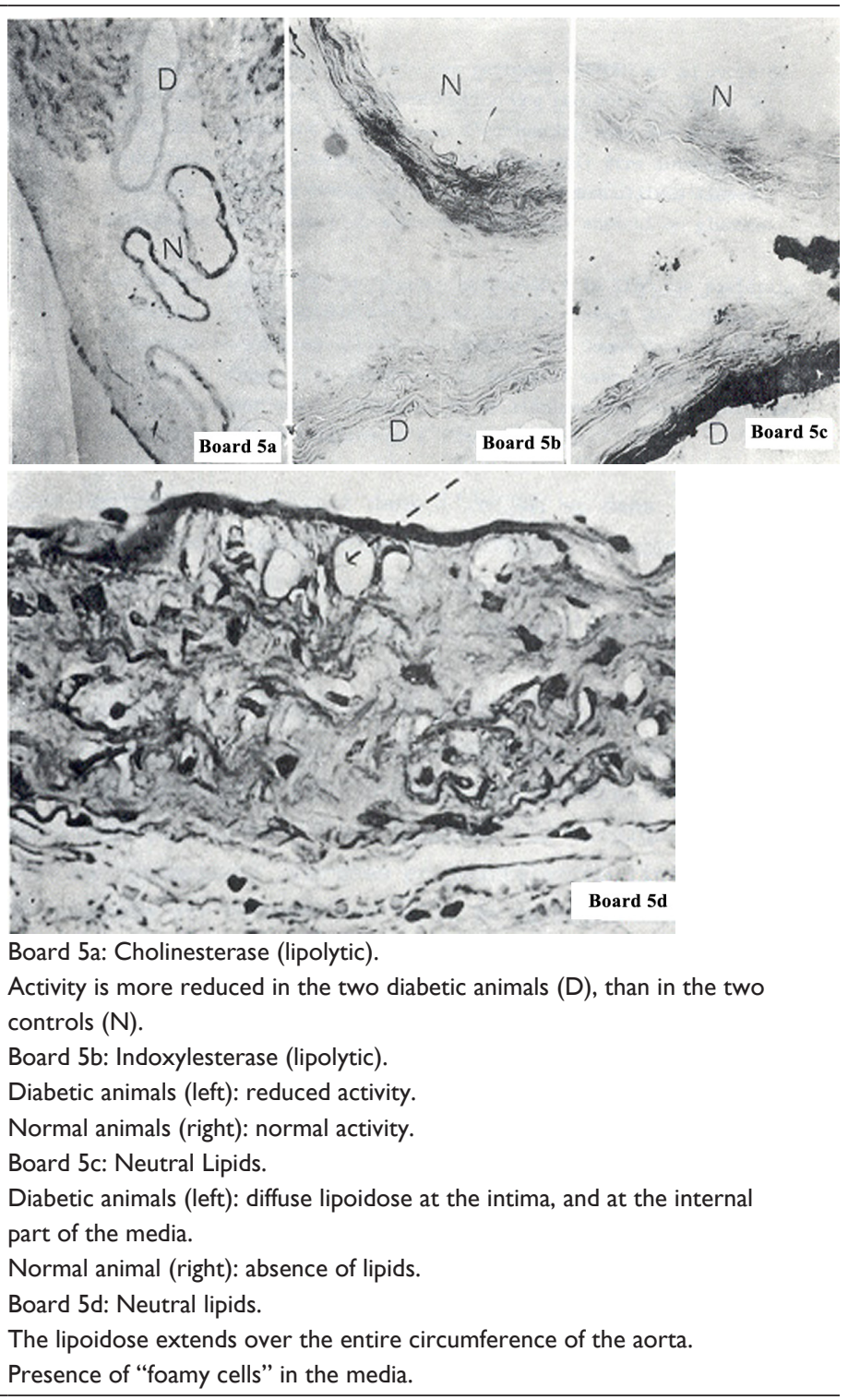

Figure 2 Comparison of aortic enzymes of Psammomys, healthy $(\mathrm{N})$ and diabetic (D).

Some enzyme activities, such as the oxidoreductases, were especially higher in the femoral and caudal arteries than in the aorta. This difference must reflect the greater abundance of cells in the media of muscular artery, but also their more pronounced contractile ability.

\section{Comparative study of aortic macromolecules in Psammomys obesus, Gerbillus gerbillus, and Rattus norvegicus}

The differences between the three species were either purely "quantitative," or "qualitative." The first were phenotypic, and involved the aerobic oxidoreductases: $\mathrm{NADH}_{2} \mathrm{DH}, \mathrm{NAD}-$ $\mathrm{PDH}_{2} \mathrm{DH}, \mathrm{SDH}, \mathrm{MAO}$, and alpha-G 6-PDH, as illustrated in Figure 1, boards 1 and 2. These images clearly show that the intensities of aerobic oxidoreductases in myocytes from the desert rodents were higher than in the Wistar rats.

The second differences were genetic. Some activities, weak in one species, could be severe in the other; alkaline phosphatase, which is considered a specific marker of endothelial plasma membrane, was strongly positive in the vasa vasorum and fibroblasts at the junction of the medialadventitial borders of the rats, whereas it was totally absent in the desert rodents. Lipolytic activities (indoxyl-naphthyl-esterase-cholinesterase) were intense in the Wistar rats but were barely noticeable in Psammomys and Gerbillus as shown in images $3 \mathrm{~b}$ and $3 \mathrm{c}$ of board 3 . The $5^{\prime}$ nucleotidase, 
a biochemical marker of tissue calcification, and probably of early atherosclerosis, was high in the desert rodents and completely absent in the Wistar rats.

Whatever the exact functional significance of these interspecific variations, they suggest the existence of subtle molecular differences in the endothelial and myocyte cell plasma membranes between the Wistar rats and the desert rodents. Lysosomal leucine aminopeptidase, which was barely detectable in the rats, was much more intense in Psammomys and Gerbillus, and suggests the existence of intense remodeling in the media, and especially in the adventitia of the latter. But the most significant difference concerns the esterases and cholinesterase, present in the aorta of Wistar rats and Gerbillus and virtually absent in Psammomys, as the lipolytic capacity of the aortic media depends largely on the activity of these enzymes. ${ }^{33}$ The comparative activity of several relatively low carboxylic esterases was the most characteristic feature of the aorta of the atherosensitive animals.

\section{Metabolic behavior of the aorta of Psammomys obesus after a diabetogenic diet}

\section{Metabolic status}

To enter the response of the aortic tissue into diabetogenic aggression, an aorta of a Psammomys that was fed HCD was removed and juxtaposed in the same block as an aorta of an animal of the same age fed with halophytes. The two aortas were treated simultaneously to study their histochemical characteristics, and then studied comparatively on the same section. This examination was repeated nine times to ensure reproducibility of measurements. The results are shown in Figure 2, boards 4 and 5 .

To determine the metabolic status of the animals in the experiment, we measured all the usual biometabolic parameters. The animals that were systematically fed the HCD became obese and developed hyperinsulinemia in an attempt to adapt to new living conditions. Of the 40 Psammomys submitted to HCD, 24 managed to regulate their blood sugar, while the other 16 animals developed significant hyperglycemia. From the sixth month, we observed an abrupt fall of plasma insulin rate in 11 of the animals in the latter group, and they became insulindependent. Glucose and blood lipid rates were very high. Ketoacidosis appeared, resulting in diabetic coma and death of the animal. Of the 16 diabetic animals selected for the histochemical study, 11 were insulin-dependent and five were not insulin-dependent.

\section{Enzymatic changes and metabolic pathways}

Enzymes attached to the pentose pathway (G6PDH), to the Krebs cycle (SDH, UDH), and to the redox of the nucleotides $\left(\mathrm{NADH}_{2} \mathrm{DH}\right.$ and $\left.\mathrm{NADPH}_{2} \mathrm{DH}\right)$ showed a trend toward activation, in the hyperglycemic animals (Figure 2, board 4). This phenomenon must be interpreted as an attempt by the SMCs of the arteries to adapt to a microenvironment enriched with glucose. However, the activity of enzymes attached to the parietal lipolysis (esterase and cholinesterase) was decreased in most animals with DS (Board V). Since, in most cases, there is a non-insulin-dependent diabetes mellitus with strong hyperinsulinemia, it can be assumed that inhibition of lipolysis in these cases is due more to excess insulin than to hyperglycemia. Neutral lipids appeared in the intima and in the internal quarter of the media in Psammomys subjected to the diabetogenic diet for nine months, and which were in a state of insulin-dependent diabetes mellitus (Figure 2, images $5 \mathrm{c}$ and $5 \mathrm{~d}$ of board 5). In these animals, lipolytic enzyme activities were greatly reduced or zero.

The SMCs, of the most inner part of the media underlying the intima, had a vacuolar cytoplasm in the preparation previously dehydrated, and therefore, are devoid of lipids. Histologically, this is the typical aspect of "cell foam" loaded with lipid droplets. The "lipoidosis" was circumferential and involved almost the full circumference of the wall; this phenomenon was more marked in the thoracic aorta of Psammomys obesus.

\section{Conclusion}

Examination of the frequency of atherosclerosis and its phenotypes shows significant differences from one species to another. These differences cannot be fully explained by environmental factors, since the three rodent species considered live in the same habitat and eat exactly the same diet. Comparative studies show that susceptibility to aortic atherosclerosis has the following traits, which were found in Psammomys:

The great abundance of GAGs inhibits lipolysis, creating fixing points for lipoproteins, which penetrate the media, and induces calcification of the extracellular matrix.

The reduced activity of enzymes related to the Krebs cycle lowers the energy capacity and leads to the danger of hypoxia; the reduced activity of lipolytic enzymes leads to accumulation of lipids that have penetrated the aortic wall.

The activity of ATPase is also reduced. This enzyme controls the level of ATP, a factor which promotes the synthesis of long fatty acid chains, and thereby, sclerogenic lipids..$^{35,36}$

The differences observed in the caudal and femoral arteries of the three species studied were especially of the 
histoenzymologic type. The very low pyroninophilicity of the myocyte cytoplasm reflects its low content of ribonucleoproteins. The activities of some oxidoreductases were higher in these arteries than in the aorta. This difference must reflect the greater cell density in the media of the muscular artery, but may also induce a better contractility. Finally, the arterial metabolism of Psammomys appears closer to that of Gerbillus than to that of Wistar rats. In our precedent contribution, we show that histological characterization demonstrates the typical alterations observed in atherosclerosis and that Psammomys obesus is an excellent animal model in which to study the progression of T2D and the development of atherosclerosis. ${ }^{36}$ The observations reported in this paper reveal that the atherosensitivity of Psammomys is essentially of enzymatic origin, as has been observed in other atherosensitive animals. ${ }^{35}$ Psammomys obesus is, then, very appropriate for the experimental study of the development of atherosclerosis and diabetes.

\section{Acknowledgments}

We are very grateful to Prof Colin J Marsden for reviewing and correcting the English in this manuscript (colin. marsden@irsamc.ups-tlse.fr). Thanks to our coworkers in Béni-Abbès, where our research originated, and to our coworkers at CPMC, CHU Mustapha-Bacha of Algiers. This research is supported by the "DGRSDT-MESRS" of Algeria. All authors approved the final version to be published.

\section{Disclosure}

The authors report no conflict of interest in this work.

\section{References}

1. Elbaz M. Physiologie de la vasomotricité coronaire et implications en pathologie coronaire, CHU Toulouse, Inserm U466. MT Cardio. 2005; 1(1): $17-27$.

2. Renard C, Fredenrich A, Van Obberghen E. L'athérosclérose accélérée chez les patients diabétiques. Métabolismes Hormones Diabètes et Nutrition. 2004; VIII(3):131-136.

3. Wautier JL, Wautier MP. Aspects physiopathologiques de l'angiopathie diabétique. Diabetes Metab. 1999;25(3):21-26.

4. Leutenegger M. Macroangiopathie diabétique, physiopathologie, implications thérapeutiques. STV. 1995;7(4):247-256.

5. Zhang Q, Ames JM, Smith RD, Baynes JW, Metz TO. A Perspective on the Maillard Reaction and the Analysis of Protein Glycation by Mass Spectrometry: Probing the Pathogenesis of Chronic Disease. J Proteome Res. 2009;8(2):754-769.

6. Rosenfeld ME, Polinsky P, Virmani R, Kauser K, Rubanyi G, Schwartz SM. Advanced atherosclerotic lesions in the innominate artery of the apo E knockout mouse. Arterioscler Thromb Vasc Biol. 2000;20(12): $2587-2592$

7. Walder KR, Fahey RP, Morton GJ, Zimmet PZ, Collier GR. Characterization of obesity phenotypes in Psammomys obesus (Israeli sand rats). Int J Exp Diabetes Res. 2000;1(3):177-184.
8. Walder K, Oakes N, Fahey RP, Cooney G, Zimmet P, Collier GR. Profile of dyslipidemia in Psammomys, an animal model of the metabolic syndrome. Endocr Regul. 2002;36(1):1-8.

9. Ziv E, Kalman R, Hershkop K, Barash V, Shafrir E, Baron H. Insulin resistance in the NIDDM model Psammomys obesus in the normoglycaemic, normoinsulinaemic state. Diabetologia. 1996;39(11): 1269-1275.

10. Lehotsky J, Kaplan P, Racay P, Mezesova V, Raeymaekers L. Distribution of plasma membrane Ca2+ pump (PMCA) isoforms in the gerbil brain: effect of ischemia-reperfusion injury. Neurochem Int. 1999;35(3):221-227.

11. Nagata E, Tanaka K, Suzuki S, et al. Selective inhibition of inositol 1,4,5-triphosphate-induced $\mathrm{Ca} 2+$ release in the $\mathrm{CA} 1$ region of the hippocampus in the ischemic gerbil. Neuroscience. 1999;93(3): 995-1001.

12. Phillis JW, Estevez AY, Guyot LL, O'Regan MH. 5-(N-Ethyl$\mathrm{N}$-isopropyl)-amiloride, an $\mathrm{Na}+\mathrm{H}+$ exchange inhibitor, protects gerbil hippocampal neurons from ischemic injury. Brain Res. 1999;839(1):199-202.

13. Oueslati S, Trabelsi N, Boulaaba M, Legault J, Abdelly C, Ksouri R. Evaluation of antioxidant activities of the edible and medicinal Suaeda species and related phenolic compounds. Ind Crops Prod. 2012;36(1):513-518.

14. Hadjiisky P, Renais J, Scebat L. A comparative study of the arterial tissue metabolism in atherosensitive and atheroresistant species. I. Comparison between rabbit and rat aortas. Paroi Arterielle. 1981;7(4): 155-165.

15. Nowak RM. Walker's Mammals of the World. 6th ed. Baltimore, Maryland, USA. John Hopkins University Press; 1999:1054-1055.

16. Directive 2010/63/EU of the European Parliament and of the Council of 22/07/2010 on the Protection of Animals Used For Scientific Purposes. Official Journal of the EU 20.10.2010: L276/33-79

17. McManus GC. Periodic Acid Schiff (PAS) for the demonstration of glycogen. In: Bancroft JD, Stevens A, editors. Manual of Histological Demonstration Techniques. Theory and Practice of Histological Techniques. 2nd ed. 1946:188.

18. Pearse AGE. Histochemistry. Theoretical and Applied. Churchill Livingstone, Edinburgh. 1972.

19. Hess R, Scarpelli DG, Pearse AGE. The cytochemical localization of oxidative enzyme. Pyridine nucleotide linked dehydrogenase. J Biophys Biochem Cytol. 1958;4(6):753-760.

20. Gerebtzoff MA. Contribution histochimique à l'étude de lactate déshydrogénase et de ses isoenzymes. Pathol Biol (Paris). 1968;16: 601-608.

21. Van Noorden CF, Frederiks WM. Enzyme Histochemistry. A Laboratory Manual of Current Methods. 1st ed. Oxford: Oxford University Press; 1992:116-117.

22. Wegman R, Gerzelli G. La gluco-6-phosphate déshydrogénase et ses corrélations avec les substrats voisins du glucose-6-phosphate. Role de l'hexokinase. Ann Histochim. 1961;6:111-125.

23. Brown GG. An Introduction to Histotechnology. New York: AppletonCentury-Crofts; 1978:346-347.

24. Glenner GG, Burtner HI, Brown GW. The histochemical demonstration of monoamine oxidase activity by tetrazoline. J Histochem Cytochem. 1957;5(6):591-600

25. Denizot, JP. Enzyme activity during the metabolism of glycogen. Histochem Cell Biol. 1978;55(2):117-128.

26. Sie HG, Sawer D, Fishman WH. Enzymorphologic demonstration of gluco-6-phosphate dependant glycogen synthetase in mouse liver. J Histochem Cytochem. 1966;14(3):247-253.

27. Karnowsky MJ, Roots L. The 'direct coloring' thiocholine method for cholinesterase. J Histochem Cytochem. 1964;12:219-221.

28. Barka R, Anderson PJ. Histochemical methods for acid phosphatase using hexazonium pararosanilin as coupler. J Histochem Cytochem. 1962; 10:741-753. 
29. Kaltenbach JC, Fry AE, Leius VK. Histochemical patterns in the tadpole tail during normal and thyroxine-induced metamorphosis II. Succinic dehydrogenase, $\mathrm{Mg}$ - and $\mathrm{Ca}$-adenosine triphosphatases, thiamine pyrophosphatase, and 5'-nucleotidase. Gen Comp Endocrinol. 1979;38(1):111-126.

30. Seligman M, Tsou KC, Putenberg SH, Cohen RB. Histochemical demonstration of D-glucoronidase with a synthetic substrate. J Biophys Biochem Cytol. 1956;25;2(5):487-502.

31. Wachstein M, Bradshaw M, Ortiz JM. Histochemical demonstration of mitochondrial ATP as activity in tissue sections. J Histochem Cytochem. 1962;10:65-74.

32. Dodgson KS, Spencer B, Thomas J. Studies on sulphatases. II. The assay of the arylsulphatase activity of rat tissues. Biochem J. $1953 ; 53(3): 452-457$.
33. Padikula UA, Herman E. Specificity of histochemical method for adenosine-triphosphatase. J Histochem Cytochem. 1955;3:170-196.

34. Binkley F, Leibach F, King N. A new method of peptidase assay and the separation of three leucylglycinases of renal tissues. Arch Biochem Biophys. 1968;128(2):397-405.

35. Wu BJ, Else PL, Storlien LH, Hulbert AJ. Molecular activity of $\mathrm{Na}+/$ $\mathrm{K}+$-ATPase from different sources is related to the packing of membrane lipids. The Journal of Experimental Biology; 2001; 204:4271-4280.

36. Haag M, Dippenaar NG. Dietary fats, fatty acids and insulin resistance: short review of a multifaceted connection. Med Sci Monit. 2005;11(12): RA359-367.

37. El-Aoufi S, Gendre P, Sennoune SR, Rigoard P, Maixent JM, Griene L. A high calorie diet induces type 2 diabetes in the desert sand rat (Psammomys obesus). Cell Mol Biol. 2007;53:942-951.

\section{Publish your work in this journal}

Diabetes, Metabolic Syndrome and Obesity: Targets and Therapy is an international, peer-reviewed open-access journal committed to the rapid publication of the latest laboratory and clinical findings in the fields of diabetes, metabolic syndrome and obesity research. Original research, review, case reports, hypothesis formation, expert opinion and commentaries are all considered for publication. The manuscript management system is completely online and includes a very quick and fair peer-review system, which is all easy to use. Visit http://www.dovepress.com/testimonials.php to read real quotes from published authors. 